\title{
Smoking-related thoughts and microbehaviours, and their predictive power for quitting
}

\author{
Lin Li, ${ }^{1}$ Ron Borland, ${ }^{1}$ Geoffrey T Fong, ${ }^{2,3}$ Yuan Jiang, ${ }^{4}$ Yan Yang, ${ }^{4}$ Lili Wang, ${ }^{4}$ \\ Timea R Partos, ${ }^{1}$ James $\mathrm{F}$ Thrasher ${ }^{5}$
}

${ }^{1}$ Research Division, Cancer Council Victoria, Melbourne, Australia

${ }^{2}$ Department of Psychology, University of Waterloo, Waterloo, Canada

${ }^{3}$ Ontario Institute for Cancer Research, Toronto, Canada

${ }^{4}$ Tobacco Control Office, Chinese Center for Disease Control and Prevention, Beijing, China

${ }^{5}$ Department of Health Promotion, Education \& Behavior, Arnold School of Public Health, University of South Carolina, Columbia, USA

\section{Correspondence to}

Dr Lin Li, Research Division, Cancer Council Victoria,

615 St Kilda Road, Melbourne, Vic 3004, Australia;

Lin.Li@cancervic.org.au

Received 8 October 2013 Accepted 29 January 2014 Published Online First 25 February 2014

\section{CrossMark}

To cite: Li L, Borland $R$, Fong GT, et al. Tob Control 2015:24:354-361

\section{ABSTRACT}

Background Negative attitudes to smoking are wellestablished predictors of intentions to quit and quit behaviours, but less attention has been given to whether quitting is influenced by smoking-related thoughts and microbehaviours that reflect a concern about smoking. Objectives This paper aimed to describe the occurrence of smoking-related thoughts and microbehaviours among Chinese smokers, and to examine their predictive power for making quit attempts and sustained abstinence.

Methods The data came from the first three waves of the International Tobacco Control China Survey. Four measures of recent thoughts about smoking and two microbehaviour measures (collectively referred to as microindicators) were examined.

Results Most smokers (around three-quarters) reported thinking about harms of smoking to themselves or to others at least occasionally, and an increasing minority reported the two microbehaviours of prematurely butting out cigarettes and forgoing them. All microindicators were positively related to subsequent quit attempts in individual predictor analyses, but only serious thoughts about quitting and butting out cigarettes had independent relationships. Overall, there was no clear relationship between these microindicators and sustained abstinence.

Conclusions There was a moderately high level of occurrence of recent smoking-related thoughts and microbehaviours among the Chinese adult smokers in the six cities studied. Like in the West, microindicators of concern about smoking were positively associated with subsequent quit attempts, but unlike in the West, they were largely unrelated to sustained abstinence.

\section{INTRODUCTION}

Negative attitudes to smoking reliably predict intentions to quit smoking and quitting behaviour. $^{1-5}$ Recently, motivated by research on the importance of attitude accessibility, ${ }^{6} 7$ a phenomenon typically measured in experimental contexts, but which might be indicated by the frequency with which relevant thoughts occur, there has been interest in seeing whether such measures add predictive capacity to models of quitting. ${ }^{4} 899$ In Western countries, the frequency of negative thoughts about smoking and of thoughts about quitting have been shown to predict subsequent quitting activity. ${ }^{189} \mathrm{~A}$ few studies have also found that microbehaviours that result from negative thoughts, such as forgoing a cigarette or butting out a cigarette before it is finished are also associated with increased subsequent likelihood of quitting. ${ }^{489}$ For the purpose of this paper, we refer to frequency of such thoughts and microbehaviours collectively as 'microindicators of concern about smoking'.

While microindicators appear to be reliably associated with subsequently making quit attempts, their relationships with quit success among those who try, is less clear. The balance of evidence suggests that they are associated with greater relapse. Borland et $a l^{1}$ found that the frequency of prematurely butting out cigarettes due to noticing cigarette pack warnings was positively associated with subsequent quit attempts, however, it was negatively associated with at least 1 month of sustained abstinence among those who made quit attempts. Borland $e t a l^{8}$ also found that forgoing cigarettes as a result of noticing health warnings on packs was a consistent prospective predictor of making quit attempts, but had no consistent relationship with maintaining abstinence for at least 1 month. ${ }^{8}$

Partos $e t a l^{9}$ reported that, overall, over $50 \%$ of adult smokers in the International Tobacco Control Four Country Study (the ITC-4 study, covering Australia, Canada, the UK and the USA) reported that they often thought about the harms of smoking to themselves in the last month, and around 30\% reported having stubbed out cigarettes before finishing in the last month, and the rates were generally consistent between 2002 and 2007. They found that stubbing out a cigarette before finishing, foregoing a cigarette, and thinking about the harms of smoking to oneself and to others, all independently predicted subsequent quit attempts; however, only more frequent stubbing out, foregoing a cigarette and thinking about the cost of smoking were associated with a reduced likelihood of achieving sustained abstinence (for at least 6 months). ${ }^{9}$ The authors suggested that although the microindicators measure motivation to quit, they are lesser acts than quitting, and may, therefore, be indicative of smokers who have more than average difficulty in staying quit. That is, in a context where most smokers have tried and failed multiple times, ${ }^{10}$ those who more frequently engage in these microbehaviours, rather than just trying to quit, may lack the ability to stay quit. These findings suggest a dynamic, whereby greater activity may reflect high motivation and reduced perceived capacity to act successfully. ${ }^{11}$

This analysis raises the question of whether we might expect to find the same pattern of results in countries like China where the history of tobacco control is comparatively short, and where pressures to quit and the number of failed quit attempts might be relatively lower.

Compared to Western countries, such as Australia and Canada, China has implemented relatively few 
antismoking programmes and policies. China ratified the WHO Framework Convention on Tobacco Control (FCTC) in October 2005 and started to implement the international health treaty from early 2006. During the study period (2006-2009), the Chinese government adopted some tobacco control measures, including public education campaigns. The public education efforts included sporadic educational activities (such as those conducted during the World No Tobacco Day periods) and more recently a nationwide awareness campaign, starting in $2008 .{ }^{12}$ It used the major national media (including the Chinese Central Television (CCTV) network) to report and convey key messages on tobacco control. ${ }^{12}$ The activity appears to have been successful in increasing public awareness of smoking-related harms, albeit modestly. ${ }^{13}$ In October 2008, China also introduced new and somewhat stronger cigarette package health warnings that met FCTC minimum requirements on size, with the warning occupying $30 \%$ of the front and back of the package. However, they were text-only warnings, did not include FCTC-recommended pictures, and there were no other design elements that set the health warnings apart from the rest of the package. Evaluation to date, suggests their impact to be minimal. ${ }^{14}$

Little is documented about the occurrence of smoking-related thoughts and microbehaviours among Chinese adult smokers, and how these microindicators relate to cessation outcomes in the Chinese context. In light of existing knowledge from previous research in the West, this paper aimed to (1) describe the occurrence of microindicators of concern about smoking among Chinese adult smokers and (2) examine whether the microindicators' generally positive associations with quit attempts and negative associations with quit success are replicated in Chinese smokers. We predict that the positive relationships with quit attempts found in the West will be replicated, but not the negative relationships with relapse, as in China there will be less smokers highly motivated to quit but with low capacity to do so.

\section{METHODS}

\section{Data source and participants}

The data came from the first three waves of the ITC China Survey for adult smokers, a prospective face-to-face cohort survey of adult smokers in six cities in China: Beijing, Shenyang, Shanghai, Changsha, Guangzhou and Yinchuan. Wave 1 data was collected between April and August 2006, Wave 2 data between October 2007 and January 2008, and Wave 3 data between May and October 2009. A detailed description of the methods of the ITC China Survey has been reported by Wu et al, ${ }^{15}$ and more detail is available at (http://www.itcproject.org). Cities were selected based on geographical representations and levels of economic development. Within each city, a random sample was selected using a stratified multistage design. Respondents were aged 18 years or older, had smoked at least 100 cigarettes in their lifetime, and smoked at least weekly at the time of recruitment. At each wave, the sample size of smokers per city is approximately 800, with replenishment sampling (from Wave 2) from the same sampling frame used to maintain sample size across waves. ${ }^{15}$

The samples used for this study were restricted to current smokers at the time of the survey, and for prediction of subsequent quit attempts and sustained abstinence, provided outcome data at the next wave/s. A total of 4732 smokers were surveyed at Wave 1 , and 3863 were successfully followed up at Wave 2 (retention rate $=81.6 \%$ ). A total of 4568 current smokers (including newly replenished smokers) were surveyed at Wave 2, and 3677 of them were followed-up at Wave 3 (retention rate = $80.5 \%)$. At Wave 3 survey, there were 4336 current smokers, including replenishments.

\section{Measures}

Smoking-related thoughts and microbehaviours

Four questions about recent thoughts about smoking/quitting were analysed. At each survey wave, current smokers were asked how often, if at all, they thought about the following things in the past month: (1) "The harm your smoking might be doing to you"; (2) "The harm your smoking might be doing to other people"; (3) "The cost of smoking" and (4) "How often you seriously consider quitting?" Response options were 'never', 'occasionally', 'often' and 'don't know', with 'never' and 'don't know' recoded as one category.

Two microbehaviours were assessed: (1) "In the last month, have you butted out a cigarette before you finished it because you thought about the harm of smoking to your health?" (response options 'yes' and 'no') and (2) 'In the last month, have the warning labels (on cigarette packages) stopped you from having a cigarette when you are about to smoke one?" (ie, 'forgoing a cigarette', with response options 'never', 'once', 'a few times', and 'many times'; with the last three options recoded 'at least once').

\section{Covariates}

Sociodemographics measured included sex (male, female), age (18-24, 25-39, 40-54, 55 years and older), ethnic group (majority group, Han Chinese, minority group), marital status (ie, married/living together with a partner compared to 'divorced or separated', 'widowed' and 'single'), city of residence, education ('low' level of education refers to no schooling or having only primary school education, 'moderate' were those with high school or technical secondary education, and 'high' were those with a university or postgraduate degree), and income (monthly household income $<1000$ Chinese yuan (CNY) (approximately US\$150) coded as 'low income', 1000$3000 \mathrm{CNY}$ coded as 'moderate income', and those equal or greater than $3000 \mathrm{CNY}$ (US\$450) as 'high income', and those who did not provide information coded as 'don't know').

Smoking-related measures included Heaviness of Smoking Index (HSI, with a range from 0 to 6 ), ${ }^{16}$ intention to quit (planning 'within the next month', 'within the next 6 months', 'sometime in the future, beyond 6 months', 'not planning to quit', and 'don't know'), self-efficacy for quitting successfully (4-point scales: 'not at all sure' to 'extremely sure') and length of last serious quit attempt ('no attempt', 'less than 1 month', '1-6 months', and ' 7 months or more').

For additional analysis, we also used a combined measure of a smoker's reported exposure to antismoking messages in the last 6 months. It was computed based on the total numbers of channels (out of 13 channels) in which a respondent had noticed antismoking messages (from television, radio, posters, billboards, newspapers/magazines, shops/stores, street vendors, the internet, working places, public transportation, restaurant/tea houses, entertainment venues to cigarette packs). As the index was highly skewed, the square root of the total numbers (ranged from 0 to 13) of channels of exposure was employed.

\section{Cessation outcome measures}

1. Quit attempts. Quit attempts were assessed at follow-up (ie, Waves 2 and 3) based on the answer to "Since we last talked to you (in the last survey date), have you made any attempts to stop smoking?”, or if a respondent reported no longer smoking at the time of the follow-up survey.

2. Sustained abstinence. Among those who had made quit attempts, we assessed if they had achieved sustained 
abstinence for at least 6 months on any attempt made in between waves, by asking "What is the longest time that you stayed smoke-free since (in the last survey date)?" Regardless of whether they had relapsed to smoking by the corresponding follow-up survey, anyone who reported a period of 6 months or longer met this criterion. For those who were currently quit, but reported being quit for less than 6 months, we used the next wave's data to determine their subsequent length of abstinence, where possible. If not, they were excluded from analyses relating to sustained abstinence.

\section{Data analysis}

Taking into consideration the correlated nature of the data within respondents across survey waves, we used the Generalised Estimating Equations (GEE) approach to compute parameter estimates using a specification for the binomial distribution of the binary dependent variables. We also specified an unstructured within-subject correlation structure, and parameter estimates were computed using robust variance. Our large sample size allowed us to assume an unstructured correlation structure in GEE, which enabled estimation of all possible correlations between within-subject responses and adjustment for them in variance estimation.

Our main analyses were to examine the longitudinal association between microindicators (of Waves 1 and 2) and subsequent quit attempts and sustained abstinence, and we conducted the GEE analyses in three steps. First, each individual microindicator was included in the model (separately), controlling for city of residence, age, sex, ethnicity, marital status, highest level of education attained, annual household income, cohort and wave. Second, in an 'intermediate step', all microindicators were included in one model, controlling for the same covariates. Third, in 'fully adjusted analysis' we also added the following smoking-related variables: HSI, self-efficacy of quitting, length of last serious quit attempt, and intention to quit. In GEE modelling, city of residence, sex and ethnicity were treated as time-invariant, whereas, the other sociodemographics and all smoking-related characteristics were treated as time-varying variables.

For models predicting subsequent quit attempts, step one included 4532 unique individuals providing up to 7430 observations across three waves (any individual could contribute up to two observations); the 'intermediate step' included 4524 individuals with up to 7416 observations; and the 'fully adjusted analysis' included 4315 individuals providing 6861 observations. For models predicting sustained abstinence, step one included 1553 unique individuals providing up to 1843 observations; the 'intermediate step' included 1548 individuals with up to 1840 observations; and the 'fully adjusted analysis' included 1415 individuals providing 1674 observations.

GEE modelling was also used to examine if there were any differences in the occurrence of microindicators across three waves. In this case Wave 3 microindicators were also used. In such modelling, each microindicator was treated as a dependent variable, and 'wave' as an independent variable, and controlling for age, sex, ethnicity, marital status, highest level of education attained, annual household income and intention to quit. All analyses were conducted using Stata V.12.1.

\section{RESULTS}

\section{Sample characteristics}

Table 1 presents the characteristics of the retained sample compared with those lost to follow-up for Wave 2-Wave 3. The comparable data for Wave 1 -Wave 2 is similar in pattern. ${ }^{17}$ The characteristics were generally comparable between those retained and those lost to follow-up except for greater drop-out among relatively younger and more educated smokers. A relatively high proportion (about two-thirds) of smokers expressed no intention to quit, and almost half had low self-efficacy for quitting smoking.

\section{Occurrence of smoking-related thoughts and microbehaviours}

Table 2 presents the reported levels of smoking-related thoughts and microbehavious among current smokers over time/wave. Overall, around three-quarters thought (at least occasionally) about the harms of smoking to themselves and to others in the last month. For these two, plus frequency of seriously thinking about quitting, there was generally a significant increase across waves in reporting these 'occasionally', with 'often' declining; and for thinking about harms to others the frequency of 'never/ don't know' also declined. Thoughts about the cost of smoking were less common and declined across waves, with a greater decline between Waves 1 and 2 than between Waves 2 and 3. A considerable and increasing minority up to $37.8 \%$ at Wave 3 reported that they had butted out a cigarette in the last month, before finishing it (smaller increase between Waves 2-3 than between the first two waves). Finally, there was a significant increase in the proportion of smokers who reported forgoing cigarettes at least once in the past month (from 16.1\% at Wave 1 to $22.7 \%$ at Wave $3, \mathrm{p}<0.001)$.

We checked to see if any of these effects could have been time in sample effects (effects of resurveying), but found almost identical findings for the recontacted as compared with replenishment samples.

Given the overall increase in reporting of microindicators over time, we checked the data to see if they were related to exposure to antismoking messages and found a positive association-those who reported having engaged in microbehaviours and having smoking-related thoughts (except for thinking about the cost of smoking) were also more likely to report having been exposed to antismoking messages $(p<0.001$, data not reported here).

\section{Associations between smoking-related thoughts/ microbehaviours and cessation outcomes \\ Making quit attempts}

Of the 3863 participants who were surveyed at Wave 1 and recontacted at Wave 2, $979(25.3 \%)$ of them made at least one quit attempt between these two waves. Of the 4568 current smokers surveyed at Wave 2, 3668 of them had their Wave 2Wave 3 interwave quit attempt outcome determined. Of the 3668 participants, $1042(28.4 \%)$ made at least a quit attempt between Waves 2 and 3 .

As seen from table 3, treated individually, all microindicators were associated with being more likely to make subsequent quit attempts. When all were included in the same model (in the intermediate step), only serious thoughts and the two microbehaviours remained significant. Finally, when the other smoking-related variables were added, forgoing was no longer statistically significant, although it was suggestive of a trend, and the size of effect of the two remaining significant predictors, serious thoughts and premature butting out, declined somewhat.

Of the characteristics where there was differential attrition, younger smokers (aged 18-24 years) were more likely than the other groups to report making quit attempts. To make our analyses comparable to the ITC-4 study ${ }^{9}$ which does not include 
Table 1 Sociodemographic and smoking-related characteristics of current smokers who were surveyed at Wave $2\left(n=4568^{*}\right)$

\begin{tabular}{|c|c|c|c|c|c|}
\hline & \multicolumn{2}{|c|}{ Followed up at Wave $3(n=3677)$} & \multicolumn{2}{|c|}{ Not followed up at Wave $3(n=891)$} & \multirow{2}{*}{$\begin{array}{l}\text { p Value for group comparison } \\
\text { (followed vs not-followed) }\end{array}$} \\
\hline & $\mathbf{n}$ & \%Followed-up & n & $\%$ Not followed-up & \\
\hline City & & & & & $0.000 \dagger$ \\
\hline Beijing & 662 & 18.0 & 84 & 9.4 & \\
\hline Shenyang & 492 & 13.4 & 276 & 30.9 & \\
\hline Shanghai & 673 & 18.3 & 94 & 10.6 & \\
\hline Changsha & 644 & 17.5 & 102 & 11.5 & \\
\hline Guangzhou & 656 & 17.8 & 133 & 14.9 & \\
\hline Yinchuan & 550 & 14.9 & 202 & 22.7 & \\
\hline Gender (male) & 3483 & 94.7 & 854 & 95.9 & $0.17 \dagger$ \\
\hline Majority (Han) & 3490 & 94.9 & 841 & 94.5 & $0.59 t$ \\
\hline Marital status (\% married) & 3306 & 90.3 & 798 & 90.0 & $0.76 t$ \\
\hline Age (years) & & & & & $0.002 \dagger$ \\
\hline $18-24$ & 33 & 0.9 & 10 & 1.1 & \\
\hline $25-39$ & 554 & 15.1 & 179 & 20.1 & \\
\hline $40-54$ & 1822 & 49.6 & 425 & 47.7 & \\
\hline $55+$ & 1268 & 34.5 & 277 & 31.1 & \\
\hline Education & & & & & $0.01 \dagger$ \\
\hline Low & 436 & 11.9 & 99 & 11.2 & \\
\hline Moderate & 2474 & 67.7 & 565 & 63.8 & \\
\hline High & 746 & 20.4 & 222 & 25.1 & \\
\hline Income & & & & & $0.10 \dagger$ \\
\hline Low & 586 & 16.0 & 168 & 18.8 & \\
\hline Moderate & 1664 & 45.3 & 408 & 45.8 & \\
\hline High & 1179 & 32.1 & 256 & 28.7 & \\
\hline Don't know & 241 & 6.5 & 59 & 6.6 & \\
\hline Daily/weekly smokers & & & & & $0.53 \dagger$ \\
\hline Daily smokers & 3470 & 94.4 & 836 & 93.8 & \\
\hline Weekly smokers & 207 & 5.6 & 55 & 6.2 & \\
\hline Intention to quit & & & & & $0.56 t$ \\
\hline No intention & 2446 & 67.0 & 589 & 66.6 & \\
\hline Beyond 6 months/don't know & 680 & 18.6 & 149 & 16.9 & \\
\hline Within 6 months & 278 & 7.6 & 81 & 9.1 & \\
\hline Within 1 month & 240 & 6.6 & 63 & 7.1 & \\
\hline $\mathrm{HSI}($ mean $\pm \mathrm{SD})$ & 3549 & $2.36(0.03)$ & 853 & $2.33(0.06)$ & $0.63 \ddagger$ \\
\hline Length of last serious quit attempt & & & & & $0.90 \dagger$ \\
\hline Never tried & 1627 & 44.6 & 386 & 43.7 & \\
\hline$<1$ month & 977 & 26.7 & 240 & 27.2 & \\
\hline $1-6$ months & 755 & 20.7 & 180 & 20.4 & \\
\hline$>6$ months & 290 & 7.9 & 76 & 8.6 & \\
\hline Self-efficacy & & & & & $0.30 t$ \\
\hline Not at all sure & 1764 & 48.4 & 408 & 46.0 & \\
\hline Somewhat sure & 976 & 26.8 & 237 & 26.7 & \\
\hline Very sure & 408 & 11.2 & 113 & 12.7 & \\
\hline Extremely sure & 342 & 9.4 & 81 & 9.1 & \\
\hline Don't know & 152 & 4.1 & 48 & 5.4 & \\
\hline
\end{tabular}

the variable 'seriously consider quitting', we took it out in additional analysis, but found the same pattern of results.

\section{Sustained abstinence}

Out of the 979 participants who made quit attempts between the first two waves, 932 were able to ascertain whether they had achieved 'sustained abstinence' outcome, and 194 of them (20.8\%) achieved the criterion of at least 6 months abstinence. Out of the 1042 participants who made at least a quit attempt between Waves 2 and 3, 940 of them had their 'sustained abstinence' outcome determined, and 175 of them (18.6\%) achieved criterion abstinence.

Neither education nor age was found to be predictive of sustained abstinence. As seen from table 4, smoking-related thoughts and microbehaviours appeared to have no clear relationship with sustained abstinence. There was a weak negative effect for serious thoughts which disappeared when the other smoking-related variables were added, and a positive effect for 
Table 2 Occurrence of smoking-related thoughts and microbehaviours among current smokers, by wave

\begin{tabular}{|c|c|c|c|c|}
\hline & $\begin{array}{l}\text { Wave } 1(2006) \\
(n=4732 t)\end{array}$ & $\begin{array}{l}\text { Wave } 2(2007) \\
(n=4568 t)\end{array}$ & $\begin{array}{l}\text { Wave } 3(2009) \\
(n=4336 t)\end{array}$ & Linear effect (Coef. 95\% Cl)‡ \\
\hline \multicolumn{5}{|c|}{ Indicators of recent thoughts about smoking } \\
\hline 1. Never/don't know & 25.6 & 25.1 & 22.1 & \multirow{3}{*}{$\begin{array}{l}\text { Option 1'never' versus } 2 \text { 'occasionally' and } 3^{\prime} \text { often': }-0.007(-0.015 \text { to } 0.0004) \text { NS; } \\
\text { option } 1 \text { and } 2 \text { versus } 3:-0.037(-0.045 \text { to }-0.028)^{* * *}\end{array}$} \\
\hline 2. Occasionally & 35.8 & 39.3 & 44.6 & \\
\hline 3. Often & 38.6 & 35.6 & 33.2 & \\
\hline 2. Occasionally & 35.0 & 38.9 & 42.2 & \multirow{2}{*}{$\begin{array}{l}\text { Option } 1 \text { versus } 2 \text { and } 3:-0.025(-0.033 \text { to }-0.016)^{* * *} \text {; } \\
\text { option } 1 \text { and } 2 \text { versus } 3:-0.020(-0.029 \text { to }-0.011)^{* * *}\end{array}$} \\
\hline 3. Often & 36.7 & 34.9 & 34.1 & \\
\hline \multicolumn{5}{|c|}{ Think about the cost of smoking (\%) } \\
\hline 1. Never/don't know & 66.9 & 73.4 & 75.4 & \multirow{2}{*}{$\begin{array}{l}\text { Option } 1 \text { versus } 2 \text { and } 3: 0.118(0.061 \text { to } 0.176)^{* * *} \text {, } \\
\text { quadratic effect: }-0.019(-0.034 \text { to }-0.005)^{* *} \\
\text { option } 1 \text { and } 2 \text { versus } 3:-0.032(-0.038 \text { to }-0.026)^{* * *}\end{array}$} \\
\hline 2. Occasionally & 20.8 & 18.1 & 18.9 & \\
\hline 3. Often & 17.9 & 15.4 & 12.8 & $\begin{array}{l}\text { Option } 1 \text { versus } 2 \text { and } 3: 0.121(0.060 \text { to } 0.182)^{* * *} \text {, quadratic effect: }-0.027 \\
(-0.043 \text { to }-0.012)^{* *} \text {; } \\
\text { option } 1 \text { and } 2 \text { vs } 3:-0.025(-0.032 \text { to }-0.018)^{* * *}\end{array}$ \\
\hline \multicolumn{5}{|l|}{ Microbehaviour measures } \\
\hline \multicolumn{5}{|c|}{ Butt out a cigarette before finishing (\%) } \\
\hline No & 71.2 & 65.7 & 62.2 & \multirow[t]{2}{*}{$0.125(0.065 \text { to } 0.186)^{* * *}$, quadratic effect: $-0.020(-0.035 \text { to }-0.005)^{* *}$} \\
\hline Yes & 28.8 & 34.3 & 37.8 & \\
\hline \multicolumn{5}{|c|}{ Forgo a cigarette due to warning labels (\%) } \\
\hline Never & 83.9 & 82.2 & 77.3 & \multirow[t]{2}{*}{$0.031(0.023 \text { to } 0.038)^{\star * *}$} \\
\hline At least once & 16.1 & 17.8 & 22.7 & \\
\hline
\end{tabular}

thinking about the costs of smoking appeared at the same level of analysis. Both effects were small.

\section{DISCUSSION}

A considerable proportion of Chinese smokers expressed no intention to quit and did not believe they would succeed even if they tried. Yet, most smokers (around three-quarters) have had recent thoughts about concerns about the harms of smoking, and over the period 2006-2009, an increasing minority reported the two microbehaviours of prematurely butting out cigarettes and forgoing them. All microindicators were positively related to subsequent quit attempts in individual analyses, but only serious thoughts about quitting and butting out cigarettes had independent relationships. The finding that some microindicators were predictive of increased subsequent quit attempts is consistent with previous research in Western countries. ${ }^{9}$ Indeed it is notable that premature stubbing out of cigarettes was a positive independent predictor of making quit attempts in China and the ITC- 4 countries. ${ }^{9}$ The smaller impact of forgoing cigarettes as a result of noticing the health warnings may be related to the low potency of Chinese pack warnings. That the effects of these microindicators were at least partly independent of reported intention to quit suggests that the implications of this activity have not been fully incorporated into future quit-related plans.

While the results for China were similar to Western countries for making attempts, the findings, as predicted, show that in China these microindicators were largely unrelated to sustained abstinence. This provides some support for the notion that these indicators, particularly the microbehaviours, may indicate high motivation with low capacity in the West where most of those with the capacity to quit easily have already done so.

It is notable that in China the proportions of smokers reporting having thought about money spent on smoking were low and significantly declined across waves, and such thoughts were not related to exposure to antismoking messages. This may be because between 2007 and 2010, the real prices of cigarettes in China decreased, ${ }^{18}$ so there was less need for concern. Unlike in the West, where thinking about the cost of smoking has been found to be negatively associated with sustained abstinence, ${ }^{9}$ our data show that those Chinese smokers who had thought about the cost occasionally were more likely to achieve sustained abstinence, which suggests greater rational control.

The other cognitive microindicators changed in a non-linear fashion across waves, with a lot more 'occasional' thoughts, but somewhat fewer frequent ('often') thoughts. The reasons for this are not clear, but it may reflect a shift in reference category as at the time of Wave 1 there was very little antismoking activity, so the expectation would not have been to see any. However, across the waves, activity increased, ${ }^{13}$ and expectations of having seen at least some could thus have changed. The increase in the microbehaviours is plausibly also related to the increased antismoking activity, and as a relatively rare activity would not be expected to be affected by changes in referents. What is perhaps surprising is that some of the increase in forgoing cigarettes as a result of noticing health warnings occurred between Waves 1 and 2, before the new larger but still weak warnings ${ }^{14}$ were introduced (between Waves 2 and 3). This 
Table 3 Association between smoking-related thoughts/microbehaviours and subsequent quit attempts-generalised estimating equations (GEE) modelling results

\begin{tabular}{|c|c|c|c|c|c|c|c|}
\hline & \multirow{2}{*}{$\begin{array}{l}\% \text { Making quit } \\
\text { attempts }\end{array}$} & \multicolumn{2}{|c|}{$\begin{array}{l}\text { Individual predictor analysist } \\
\text { (7430 observations from } 4532 \\
\text { individuals } \ddagger \text { ) }\end{array}$} & \multicolumn{2}{|c|}{$\begin{array}{l}\text { Intermediate step } \\
\text { (7416 observations from } \\
4524 \text { individuals } \ddagger)\end{array}$} & \multicolumn{2}{|c|}{$\begin{array}{l}\text { Fully adjusted analysist } \\
\text { (6861 observations from } \\
4315 \text { individuals } \neq \text { ) }\end{array}$} \\
\hline & & Adjusted OR & $95 \% \mathrm{Cl}$ & Adjusted OR & $95 \% \mathrm{Cl}$ & Adjusted OR & $95 \% \mathrm{Cl}$ \\
\hline \multicolumn{8}{|c|}{ Thinking about harm to you } \\
\hline Never/don't know & 13.5 & Ref & & Ref & & Ref & \\
\hline Occasionally & 24.8 & 1.21 & 1.05 to $1.39^{*}$ & 0.92 & 0.78 to 1.09 & 0.88 & 0.73 to 1.06 \\
\hline Often & 37.6 & 1.77 & 1.53 to $2.06^{* * *}$ & 1.14 & 0.95 to 1.37 & 1.02 & 0.84 to 1.24 \\
\hline \multicolumn{8}{|l|}{ Harm to others } \\
\hline Never/don't know & 16.4 & Ref & & Ref & & Ref & \\
\hline Occasionally & 24.8 & 1.19 & 1.03 to $1.37^{*}$ & 1.02 & 0.87 to 1.21 & 1.03 & 0.86 to 1.22 \\
\hline Often & 35.7 & 1.50 & 1.31 to $1.72^{* * *}$ & 0.99 & 0.83 to 1.18 & 0.97 & 0.80 to 1.16 \\
\hline \multicolumn{8}{|l|}{ Cost of smoking } \\
\hline Never/don't know & 20.2 & Ref & & Ref & & Ref & \\
\hline Occasionally & 37.2 & 1.29 & 1.13 to $1.48^{* * *}$ & 1.05 & 0.91 to 1.21 & 0.99 & 0.85 to 1.15 \\
\hline Often & 59.1 & 1.68 & 1.42 to $1.97^{* * *}$ & 1.12 & 0.94 to 1.34 & 1.16 & 0.95 to 1.40 \\
\hline \multicolumn{8}{|c|}{ Seriously consider quitting } \\
\hline Never/don't know & 8.1 & Ref & & Ref & & Ref & \\
\hline Occasionally & 33.4 & 2.03 & 1.79 to $2.29^{* * *}$ & 1.83 & 1.60 to $2.09^{* * *}$ & 1.39 & 1.19 to $1.62^{* * *}$ \\
\hline Often & 49.1 & 3.36 & 2.92 to $2.89^{* * *}$ & 2.67 & 2.27 to $3.14^{* * *}$ & 1.73 & 1.43 to $2.09^{* * *}$ \\
\hline \multicolumn{8}{|l|}{ Butting out } \\
\hline No & 12.8 & Ref & & Ref & & Ref & \\
\hline Yes & 38.7 & 1.85 & 1.65 to $2.07^{* * *}$ & 1.43 & 1.27 to $1.62^{* * *}$ & 1.22 & 1.07 to $1.39^{* *}$ \\
\hline \multicolumn{8}{|l|}{ Forgoing } \\
\hline Never & 16.7 & Ref & & Ref & & Ref & \\
\hline At least once & 42.9 & 1.67 & 1.47 to $1.91 * * *$ & 1.25 & 1.08 to $1.44^{* *}$ & 1.11 & 0.95 to 1.29 \\
\hline \multicolumn{8}{|c|}{$\begin{array}{l}\text { *Significant at } p<0.05 ;{ }^{* *} p<0.01{ }^{* * *} p<0.001 \text {. } \\
\text { †In 'individual indicator analysis' only one smoking-related thought/micr } \\
\text { status, highest level of education attained, annual household income, } \\
\text { all the covariates as in 'individual predictor analysis'); whereas in 'fully } \\
\text { self-efficacy of quitting, length of last serious quit attempt and intentior } \\
\text { †The number in some analyses was slightly less due to missing cases. } \\
\text { Ref, reference value. }\end{array}$} \\
\hline
\end{tabular}

could be because the other health information made the pack warnings seem more relevant; that is, the media campaigns may have led smokers to pay greater attention to pack warnings. ${ }^{19}$ Whether this also accounts for the further increase between Waves 2 and 3, or is attributable to the new health warnings, or some combination of the two, is unclear.

The comparisons with Western countries (including Australia and Canada) suggest that in terms of encouraging smokers to quit, Chinese smokers are motivated in essentially the same ways as Western smokers, as shown by the findings of this study and others. ${ }^{17}$ Thus, in broad terms, and as long as they are made culturally relevant, the sorts of strategies applied successfully in the West should translate to China. In China, not many smokers have ever tried to quit (around 12\% in 1996 and increased slightly recently). ${ }^{20}{ }^{21}$ Our data suggests that the rate of trying (around 25\% between the first two waves, with about 16 months intersurvey interval), is lower than that found in the West (around 36\% for the ITC-4 countries between the first two waves, with about 8 months intersurvey interval), ${ }^{2}$ and by inference was even lower in the past. This translates into a huge difference in quitting experience and far fewer Chinese smokers with multiple failed attempts.

If our analysis is right, and fewer Chinese smokers have experienced multiple failed attempts, it suggests considerable potential for encouraging more smokers to make quit attempts, perhaps with higher success rate than now found in the West.
Indeed, the high percentage achieving at least 6 months of sustained abstinence, in the absence of programme support suggests that the provision of medication and other forms of support for smokers may be less crucial to making progress in the early stage of addressing the tobacco problem. However, we also need to be aware that education campaigns alone are not enough. An integrated approach is needed that should include awareness campaigns, stronger health warnings and support to quit when needed. As more and more smokers try and fail multiple times, there is likely to be an increased demand for help.

We are confident that the key differences in findings are not directly related to the weaker policies and programmes in China. Remember that in the West where the policies are stronger, the microindicators are inversely related to quit success. ${ }^{9}$ So if there was a direct effect of the policies, it would mean that the stronger the policies the harder it is to succeed, even though they motivate attempts. We think this highly implausible.

Since health concerns usually top the list of reasons people give for quitting smoking, ${ }^{22}$ concrete efforts need to be made to increase the public's awareness of the harms of smoking. The gap in percentage prevalence of often thinking about the harms of smoking to oneself between the Chinese smokers (less than $39 \%$ ) and those in the ITC-4 countries (over 52\%) ${ }^{9}$ warrants enhanced educational efforts. In this regard, China's newly released National Report on Harms of Smoking and 
Table 4 Association between smoking-related thoughts/microbehaviours and sustained abstinence among those who had made quit attempts—generalised estimating equations (GEE) modelling results

\begin{tabular}{|c|c|c|c|c|c|c|c|}
\hline & \multirow{2}{*}{$\begin{array}{l}\text { Per centage of } \\
\text { achieving sustained } \\
\text { abstinence }\end{array}$} & \multicolumn{2}{|c|}{$\begin{array}{l}\text { Individual predictor analysis } \uparrow \text { (1843 } \\
\text { observations from } 1553 \\
\text { individuals } \ddagger \text { ) }\end{array}$} & \multicolumn{2}{|c|}{$\begin{array}{l}\text { Intermediate step (1840 } \\
\text { observations from } 1548 \\
\text { individuals } ¥)\end{array}$} & \multicolumn{2}{|c|}{$\begin{array}{l}\text { Fully adjusted analysis } \uparrow(1674 \\
\text { observations from } 1415 \\
\text { individuals } \ddagger)\end{array}$} \\
\hline & & Adjusted odds ratio & $95 \% \mathrm{Cl}$ & Adjusted odds ratio & $95 \% \mathrm{Cl}$ & Adjusted odds ratio & $95 \% \mathrm{Cl}$ \\
\hline \multicolumn{8}{|c|}{ Thinking about harm to you } \\
\hline Never/don't know & 28.1 & Ref & & Ref & & Ref & \\
\hline Occasionally & 15.4 & 0.89 & 0.63 to 1.25 & 0.84 & 0.57 to 1.24 & 0.89 & 0.57 to 1.35 \\
\hline Often & 21.1 & 0.78 & 0.56 to 1.08 & 0.83 & 0.55 to 1.23 & 0.84 & 0.54 to 1.29 \\
\hline \multicolumn{8}{|l|}{ Harm to others } \\
\hline Never/don't know & 24.5 & Ref & & Ref & & Ref & \\
\hline Occasionally & 15.9 & 1.15 & 0.82 to 1.57 & 1.20 & 0.84 to 1.72 & 1.13 & 0.76 to 1.69 \\
\hline Often & 21.0 & 0.84 & 0.62 to 1.16 & 0.92 & 0.63 to 1.33 & 0.79 & 0.53 to 1.19 \\
\hline \multicolumn{8}{|l|}{ Cost of smoking } \\
\hline Never/don't know & 13.9 & Ref & & Ref & & Ref & \\
\hline Occasionally & 18.8 & 1.25 & 0.94 to 1.67 & 1.34 & 0.99 to 1.80 & 1.39 & 1.01 to $1.93^{*}$ \\
\hline Often & 38.4 & 0.98 & 0.69 to 1.39 & 1.01 & 0.90 to 1.47 & 1.20 & 0.79 to 1.82 \\
\hline \multicolumn{8}{|c|}{ Seriously consider quitting } \\
\hline Never/don't know & 4.6 & Ref & & Ref & & Ref & \\
\hline Occasionally & 3.8 & 0.70 & 0.52 to $0.93^{*}$ & 0.67 & 0.49 to $0.91^{*}$ & 0.83 & 0.58 to 1.17 \\
\hline Often & 4.6 & 0.84 & 0.63 to 1.14 & 0.87 & 0.62 to 1.22 & 0.81 & 0.53 to 1.22 \\
\hline \multicolumn{8}{|l|}{ Butting out } \\
\hline No & 4.1 & Ref & & Ref & & Ref & \\
\hline Yes & 4.2 & 0.93 & 0.74 to 1.18 & 0.97 & 0.75 to 1.26 & 0.84 & 0.63 to 1.12 \\
\hline \multicolumn{8}{|l|}{ Forgoing } \\
\hline Never & 4.4 & Ref & & Ref & & Ref & \\
\hline At least once & 3.5 & 1.05 & 0.80 to 1.37 & 1.14 & 0.86 to 1.54 & 1.23 & 0.89 to 1.72 \\
\hline
\end{tabular}

Secondhand Smoke ${ }^{23}$ may play an important role if its key messages are widely publicised.

This study has limitations and strengths. It is not a nationally representative sample, but only samples from large urban areas. Therefore, caution should be exercised when generalising the findings to other parts of China, especially to rural areas where smoking-related attitudes, thoughts and behaviours of smokers and tobacco industry presence may be different. ${ }^{17} 2425$ There was also differential attrition of our sample, and while we can think of no way that this would have affected the overall results, cannot rule it out. It is also important to consider the limitations that are due to reliance on self-reports. The microindicators require memory of low salience over a month, while the outcomes, likely more memorable, require memory over more than a year. It is possible that those with poor memories could add to the no indicators-no action cells, but is unlikely to have had a major impact. On the other hand, forgetting of quit attempts early in the follow-up period could lead to underestimating effect sizes. We can think of no way different memory could be responsible for the findings on sustained abstinence. There is also a possibility of socially desirable responding, ${ }^{26}$ but this is unlikely to explain the differences found between this study and those in the West. It is also possible that the increasing mass media campaigns has led to over-reporting of all quit-related thoughts and actions, but we think it unlikely, as questioning was quite intensive and respondents responded coherently. Further, there is no evidence to suggest that self-report is systematically inaccurate in population-based studies of this kind. $^{29} 27$ One of the main strengths of this study is its longitudinal design, which allowed for changes in frequencies of microindicators and quitting behaviours over time to be assessed and for prospective predictive analyses to be conducted. The use of GEE modelling allowed us to combine respondents from all three waves while accounting for inherent within-person correlation, thereby increasing our sample size and power to examine associations and detect effects.

As mentioned earlier, caution needs to be made in generalising these findings beyond urban China. That said, research should be looking to see whether the patterns found here generalise to other contexts. Our theorising has been around the differences in predictors found here being related to the relative lack of tobacco control activities and its short duration in China. If this was so, we would expect to find similar association in other countries with similar histories, where action has not driven prevalence down. By contrast, we would expect to find different results, more similar to the West, if we were to conduct a study like this in the largely Chinese ethnic cities of Hong Kong and Singapore where smoking prevalence is as low or lower than in the most successful Western countries.

In summary, the results of this study indicate that there is a moderately high level of occurrence of recent smoking-related thoughts and microbehaviours among the Chinese adult smokers in the six cities studied. Like in the West, these microindicators of concern about smoking were positively associated 
with subsequent quit attempts, but unlike in the West, they were largely unrelated to sustained abstinence. Activities to drive up quitting activity in China are likely to be essentially the same as those used successfully in the West.

\section{What this paper adds}

- Little is documented about the occurrence of smoking/ quitting-related thoughts and microbehaviours among Chinese adult smokers, and how these microindicators of concern about smoking relate to cessation outcomes in the Chinese context.

- We found that around three-quarters of current smokers in the six Chinese cities studied reported thinking about harms of smoking to themselves or to others at least occasionally in the past month, and over the period 2006-2009 an increasing minority reported the two microbehaviours of prematurely butting out cigarettes and forgoing cigarettes. Like in Western countries, such as Australia and Canada, microindicators of concern about smoking were positively associated with subsequent quit attempts; but unlike in the West, they were largely unrelated to sustained abstinence.

Correction notice This article has been corrected since it was published Online First. The surplus subtitle was removed from the article title ': findings from the International Tobacco Control (ITC) China Survey'.

Acknowledgements The authors would like to thank other members of the ITC China team for their support. The lead author (Dr Lin Li) presented some of the results and received valuable feedback at the 10th APACT Conference in Chiba, Japan in August 2013. We are grateful to the anonymous reviewers who provided useful suggestions on an earlier draft of this paper.

Contributors LL conducted literature reviews and data analyses, wrote the first draft of the manuscript and coordinated input from other authors. RB, GTF and YJ helped to design the study. RB helped to develop the broad framework for analysis, and contributed substantially to drafting the manuscript. YJ, YY and LW provided local intelligence and contributed to interpreting the data. TRP and JFT provided insights on literature review, data analysis and presentation, and contributed to interpreting the findings. All authors contributed to and approved the final version of the manuscript.

Funding This work was supported by the US National Cancer Institute at the National Institutes of Health (R01 CA100362, R01 CA125116 and P01 CA138389); the Roswell Park Transdisciplinary Tobacco Use Research Center (P50 CA111236)); Robert Wood Johnson Foundation (045734); Canadian Institutes for Health Research (57897,79551, and 115016); National Health and Medical Research Council of Australia (265903 and 450110); Cancer Research UK (C312/A3726); and Chinese Center for Disease Control and Prevention. Geoffrey T. Fong was supported by a Senior Investigator Award from the Ontario Institute for Cancer Research and a Prevention Scientist Award from the Canadian Cancer Society Research Institute. The funding sources had no role in the study design, in collection, analysis, and interpretation of data, in the writing of the report, or in the decision to submit the paper for publication.

\section{Competing interests None.}

Ethics approval Ethics approval was obtained from the Office of Research Ethics at the University of Waterloo (Waterloo, Canada), and the internal review boards at: Roswell Park Cancer Institute (Buffalo, USA), the Cancer Council Victoria (Melbourne, Australia), and the Chinese Center for Disease Control and Prevention (Beijing, China).

Provenance and peer review Not commissioned; externally peer reviewed.

\section{REFERENCES}

1 Borland R, Yong HH, Balmford J, et al. Motivational factors predict quit attempts but not maintenance of smoking cessation: Findings from the International Tobacco Control Four country project. Nicotine Tob Res 2010;12:S4-S11.

2 Hyland A, Borland R, Li Q, et al. Individual-level predictors of cessation behaviours among participants in the International Tobacco Control (ITC) Four Country Survey. Tob Control 2006;15(Suppl 3):iiï3-94.

3 Zhou X, Nonnemaker J, Sherrill B, et al. Attempts to quit smoking and relapse: factors associated with success or failure from the ATTEMPT cohort study. Addict Behav 2009;34:365-73.

4 Vangeli E, Stapleton J, Smit ES, et al. Predictors of attempts to stop smoking and their success in adult general population samples: a systematic review. Addiction 2011;106:2110-21

5 Costello MJ, Logel C, Fong GT, et al. Perceived risk and quitting behaviors: results from the ITC 4-country survey. Am J Health Behav 2012;36:681-92.

6 Fazio RH. On the automatic activation of associated evaluations: an overview. Cogn Emotion 2001;15:115-41.

7 Fazio R, Sanbonmatsu D, Powell $M$, et al. On the automatic activation of attitudes. J Pers Soc Psychol 1986:50:229-38.

8 Borland R, Yong HH, Wilson N, et al. How reactions to cigarette packet health warnings influence quitting: findings from the ITC Four-Country survey. Addiction 2009; 104:669-75.

9 Partos T, Borland R, Thrasher J, et al. The predictive utility of micro indicators of concern about smoking: Data from the International Tobacco Control 4-country study. Addict Behav 2013 (Under review).

10 Borland R, Partos TR, Yong HH, et al. How much unsuccessful quitting activity is going on among adult smokers? Data from the International Tobacco Control Four Country cohort survey. Addiction 2012;107:673-82.

11 Borland R. Understanding hard to maintain behaviour change: a dual-process approach. Oxford: Wiley Blackwell 2014

12 Li X. An Introduction to the FCTC and the MPOWER Strategic Package on Tobacco Control (published in Chinese). Chin J Health Educ 2008;24: 649-56.

13 Li L, Borland R, Yong HH, et al. Reported exposures to anti-smoking messages and their impact on smokers' subsequent quit attempts. Int I Behav Med Published online first September 2013. doi: 10.1007/s12529-013-9349-3.

14 Fong TG, Hammond D, Jiang $Y$, et al. Perceptions of tobacco health warnings in China compared with picture and text-only health warnings from other countries: an experimental study. Tob Control 2010;19(Suppl 2):i69-77.

15 Wu C, Thompson M, Fong G, et al. Methods of the International Tobacco Contro (ITC) China Survey. Tob Control 2009;19(Suppl 2):i1-5.

16 Heatherton TF, Kozlowski LT, Frecker RC, et al. Measuring the Heaviness of Smoking: using self-reported time to the first cigarette of the day and number of cigarettes smoked per day. Br J Addict 1989;84:791-800.

17 Li L, Feng GZ, Jiang Y, et al. Prospective predictors of quitting behaviours among adult smokers in six cities in China: findings from the International Tobacco Control (ITC) China Survey. Addiction 2011:106:1335-45.

18 Li Q, Hu T-w, Mao Z, et al. When a tax increase fails as a tobacco control policy: the ITC China project evaluation of the 2009 cigarette tax increase in China. Tob Control 2012;21:381.

19 Thrasher JF, Murukutla N, Pérez-Hernández R, et al. Linking mass media campaigns to pictorial warning labels on cigarette packages: a cross-sectional study to evaluate effects among Mexican smokers. Tob Control 2013;22:e57-65.

20 Yang GH, Fan LX, Tan J, et al. Smoking in China: Findings of the 1996 National Prevalence Survey. JAMA 1999;282:1247-53.

21 Li Q, Hsia J, Yang G. Prevalence of smoking in China in 2010. N Engl J Med 2011:364:2469-70.

22 American Cancer Society. Guide to quitting smoking. http://www.cancer.org/acs/ groups/cid/documents/webcontent/002971-pdf.pdf 2013.

23 Ministry of Health of China. China Report on Harms of smoking and secondhand smoke (published in Chinese). Beijing: People's Medical Publishing House, 2012.

24 Yang Y, Li L, Yong HH, et al. Regional differences in awareness of tobacco advertising and promotion in China: findings from the ITC China Survey. Tob Control 2010;19:117-24

25 Cai L, Wu X, Goyal A, et al. Patterns and socioeconomic influences of tobacco exposure in tobacco cultivating rural areas of Yunnan Province, China. BMC Public Health 2012;12:842

26 UNFPA. Population and reproductive health programmes: applying rapid anthropological assessment procedures. New York: UNFPA, 1997.

27 Fathelrahman A, Li L, Borland R, et al. Stronger pack warnings predict quitting more than weaker ones: findings from the ITC Malaysia and Thailand surveys. Tob Induc Dis 2013:11:20.http://www.tobaccoinduceddiseases.com/content/pdf/ 1617-9625-11-20.pdf 